\title{
Caesarean section by maternal age group among singleton deliveries and primiparous Japanese women: a secondary analysis of the WHO Global Survey on Maternal and Perinatal Health
}

\author{
Kyoko Yoshioka-Maeda ${ }^{1}$, Erika Ota ${ }^{2 *}$, Togoobaatar Ganchimeg ${ }^{2,3}$, Mariko Kuroda ${ }^{1}$ and Rintaro Mori ${ }^{2}$
}

\begin{abstract}
Background: The rising caesarean section rate is an important public health concern that in turn increases maternal and perinatal risks of adverse effects, unnecessary medical consumption, and inequities in worldwide access. The aim of this study was to investigate caesarean section indications by maternal age group and examine the association between age and caesarean section in primiparous Japanese women with singleton births.

Methods: We analyzed the Japanese data of primiparous women with singleton births from the WHO Global Survey on Maternal and Perinatal Health to compare maternal and neonatal characteristics and outcomes between groups with and without caesarean section. Women were divided into 3 maternal age groups $(\leq 29,30$ to 34 and $\geq 35$ years). We performed multivariable logistic-regression analysis to identify characteristics associated with caesarean section.

Results: Of the 3245 women with singleton births were included in the Japanese data, 610 women (18.8 \%) delivered by caesarean section, half of whom $(n=305)$ were nulliparous. We included singleton nulliparous women (1747 deliveries) in our analysis. The maternal age 35 years old was associated with higher risks for all caesarean section (adjusted odds ratio [AOR] 1.89, $95 \% \mathrm{Cl} 1.28-2.78$ ) and emergency antepartum caesarean section (AOR 2.26, $95 \% \mathrm{Cl}$ 1.49-3.40). Intrapartum caesarean section, which is mainly performed for obstetric indications, was not higher among the older maternal age group.

Conclusion: In Japan, advanced maternal age significantly increased the risk for caesarean section; however, intrapartum caesarean section was not higher risk among the older age group. Management of maternal complications would help to reduce the rate of caesarean sections and associated unnecessary medical consumption.
\end{abstract}

Keywords: Advanced maternal age, Caesarean section, Pregnancy, Risk factors

\section{Background}

Despite a decline in the overall birth rate in many developed countries, delayed childbearing has increased in the last few decades as a result of social, educational and economic factors [1]. Childbearing at 35 years or older is commonly defined as advanced maternal age $[2,3]$.

\footnotetext{
* Correspondence: otaerika@gmail.com

${ }^{2}$ Department of Health Policy, National Center for Child Health and Development, Tokyo, Japan

Full list of author information is available at the end of the article
}

Previous studies have shown higher risk of adverse pregnancy outcomes including preterm birth, low birth weight, stillbirth, pre-eclampsia, gestational hypertension, gestational diabetes, and delivery of small- or largefor-gestational-age neonates, and obstetric interventions like caesarean section (CS) and assisted vaginal delivery in women of advanced maternal age [4-9].

The World Health Organization (WHO) recommends that the appropriate rate of CS is not above $15 \%$ [10]. However, data from the Organization for Economic Co- 
operation and Development (OECD) shows that the average rate of CS was $26 \%$ in 2011, which has doubled over two decades [11]. In Japan, although the number of deliveries has decreased, the rate of CS increased $8 \%$ in 1984, and doubled in 2008 to $23.3 \%$ [12]. Previous studies on pregnancy outcomes in advanced maternal age have shown conflicting findings, although most have suggested an increased risk of CS in older women. These studies, however, featured different settings or small sample sizes, and failed to distinguish between elective and emergency CS, and adjustment for potential confounders [13-15]. To address this gap, we conducted a secondary analysis using Japanese data from the WHO Global Survey on Maternal and Perinatal Health (WHOGS), which included 10 health institutions from Japan. The aim of this study was to investigate CS indications by maternal age group, and examine the association between age and CS in primiparous Japanese women with singleton birth.

\section{Methods}

\section{Study design and settings}

The WHOGS was a multi-country facility-based crosssectional study conducted between 2004 and 2008 including 24 countries and 373 facilities in Asia, Africa and Latin America [16]. The study methodology of the survey is explained elsewhere in detail [17-19]. In brief, a multi-stage stratified sampling design was used to select the sample of countries and health facilities across the world. Twentyfour countries were selected from $12 \mathrm{WHO}$ regions, and in each country the capital city and two provinces were sampled randomly. Further, seven health facilities with at least 1000 deliveries per year that were capable of performing CS were randomly selected from each these areas. If there were less than 7 facilities, all facilities in that selected areas.

\section{Data collection}

We compiled data from the WHOGS of 3356 women and their infants collected from 10 facilities in Tokyo, Okayama and Nagano prefectures in 2008. All women giving birth in participating health institutions over a three-month period in 2008 were recruited in this study. Individual and health institution data were collected using standard forms. Individual data was obtained from medical records by trained health staff before hospital discharge or the $8^{\text {th }}$ day postpartum for mothers and the $7^{\text {th }}$ day after birth for neonates, with no identification of individuals involved. Collected data included maternal demographics, history of previous pregnancies, medical conditions and complications during the last pregnancy, mode of delivery and birth outcomes. Health institutional data were obtained by interview with the director or head of obstetrics. The data included were: infrastructure, basic emergency medical and obstetric care, availability of laboratory tests, anesthesiology resources, intensive care units, human resources and training. The study follow-up period was conducted at 8 days postpartum for mothers, and at 7 days after birth for newborns.

\section{Study sample and variables}

In our analysis, we included all primiparous women with singleton deliveries from the 10 participating health institutions in Japan. Women who gave birth for the first time were defined as primiparous. Multiple births, and women who had given birth one or more times, were excluded from the study sample.

The main exposure variable of maternal age was categorised into three groups: ages 20-29, 30-34 and 35 years or older. Outcomes were pregnancy and labour complications, and mode of delivery. The following pregnancy and labour complications were included: maternal hypertension (presence of having pregnancy-induced hypertension, preeclampsia and/or eclampsia), prelabour rupture of membranes, vaginal bleeding in $2^{\text {nd }}$ half of pregnancy, fetal growth impairment, preterm birth ( $<37$ weeks) and low birth weight $(<2500 \mathrm{~g})$. Mode of delivery was categorised as spontaneous vaginal delivery, instrumental vaginal delivery and CS. Further CS was categorised as elective CS (defined as CS performed before the onset of labour for medical and obstetric indications or at the request of the mother), emergency antepartum CS (defined as CS performed before onset of labour for medical and obstetric indications) and intrapartum CS (defined as CS performed after the onset of labour for failure to progress, failure of induction of labour, fetal distress or intrapartum hemorraghe). Available indications for CS in the dataset were as follows: pre-/eclampsia, suspected fetal growth impairment, fetal distress, failure to induction, cephalo-pelvic disproportion, breech or malpresentation, and other fetal, maternal and obstetric indications. We created the variable named "having two and more medical indications for CS" for women who presented with two and more indications for CS.

Available individual variables in the dataset were: marital status (married/cohabiting and single), maternal education, number of antenatal care visits, maternal pre-pregnancy body mass index (BMI) (25.0 and $>25 \mathrm{~kg} / \mathrm{m}^{2}$ ), height $(<1.5 \mathrm{~m}$ and $>1.5 \mathrm{~m})$, pre-existing medical conditions, gestational age at delivery $(<37,37$ to 41 and $\geq 41$ weeks) and birth weight $(<2500,2500$ to 4000 and $\geq 4000 \mathrm{~g})$. As maternal education was missing for approximately $25 \%$ of women in the dataset, we excluded this variable from the analysis. A medical condition was defined as the presence of any of the following: chronic hypertension, cardiac/renal diseases, chronic respiratory conditions, diabetes mellitus, sickle cell anaemia, severe anaemia and pyelonephritis or urinary infection. 
Type of health institution was categorised by ownership as public or private institutions. WHOGS data from Japan is not publicly available.

\section{Ethical approval}

Preceding this analysis, ethical approval was obtained from ethical review board of the WHO and each hospital.

\section{Statistical analysis}

We used frequencies to examine the study population characteristics, pregnancy and labour complications, and indications for CS among maternal age groups.

The risks of maternal age for all CS, elective CS, emergency antepartum CS and intrapartum CS were explored separately via multivariable logistic regression analysis. For each regression analyses, marital status, maternal height, pre-existing medical conditions, birth weight and type of health institution were considered as confounders. Because of strong correlation between maternal pre-pregnancy and maternal height (correlation coefficient $=0.9$ ), only maternal height included in the regression analyses. The youngest age group (20 to 29 years of age) served as a reference group in the multivariable analyses. All estimates of association we accounted for the WHOGS study design as clustering of women within facilities and facilities with selected areas. The point and variance estimation were obtained by using the first-order Taylor linearization. Health institutions were considered as primary sampling units and areas as strata. Pearson $x^{2}$ statistics and multivariable logistic regression analysis were conducted accounting for multistage cluster sampling, using "svy" procedure in STATA 13.1 (Statacorp, College Station, TX, USA). Statistical significance was defined as $p<0.05$.

\section{Results}

The WHOGS data included 3356 deliveries from 10 facilities in three prefectures in Japan during the study period. After excluding for multiple births (110 deliveries) and missing data on mode of delivery ( 1 delivery), 3245 singleton births remained. Of these singleton births, 610 $(18.8 \%)$ women delivered by CS, and half of them $(n=$ 305) were nulliparous. A total of 1747 nulliparous women with singleton neonates were included in this analysis. The study population consisted of 702 (40.2 \%) women aged 29 years or younger, 677 (38.8 \%) aged $30-34$ years, and $368(21.0 \%)$ aged 35 years or older (Fig 1).

Table 1 shows the characteristics of the study population. Women aged 35 years or older were more likely to have 12 or more antenatal care visits $(47.7 \%$ vs $36.3 \%$ in women aged $\leq 29$ years and $45.4 \%$ in women aged 30-34 years), and a pre-existing medical condition $(26.5 \%$ vs $14.0 \%$ in women aged $\leq 29$ years and $15.1 \%$ in women aged $30-34$ years). Women aged $\leq 29$ years

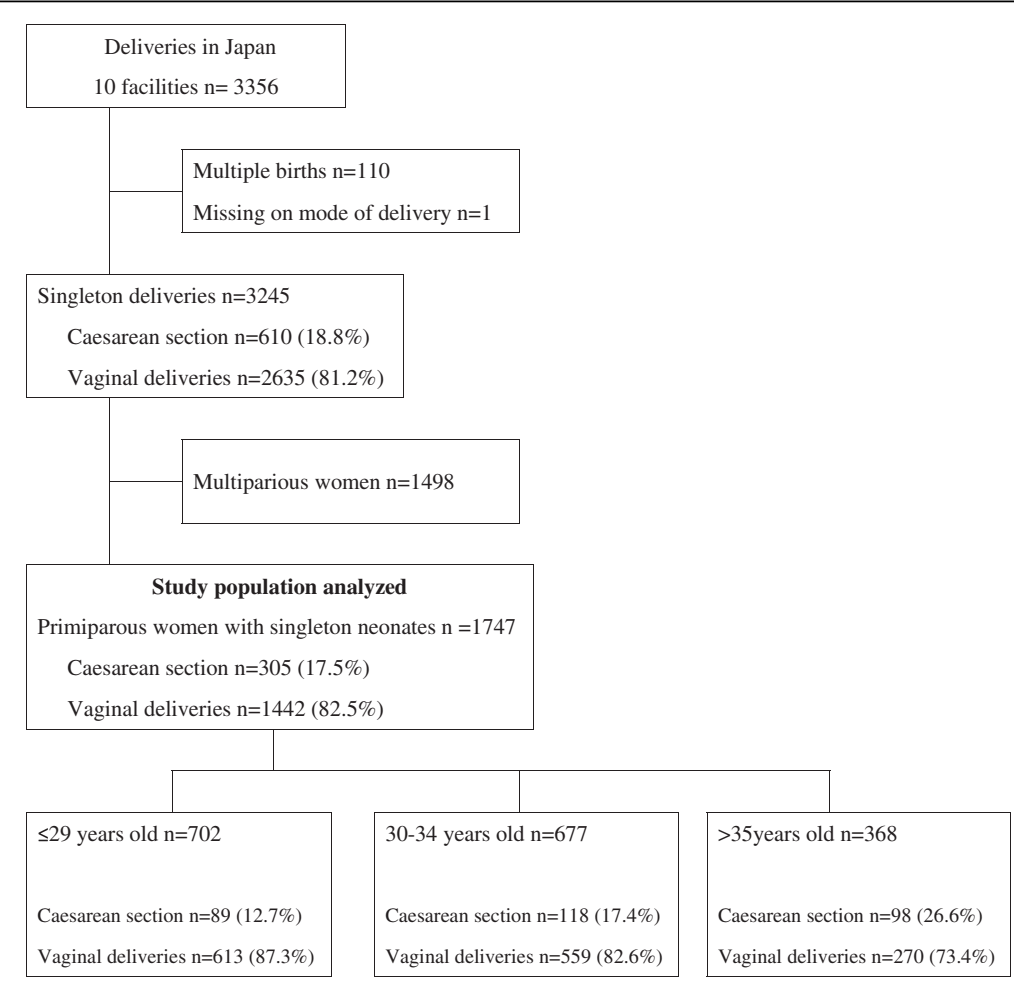

Fig. 1 Study flow chat 
Table 1 Characteristics of nulliparous women with singleton birth $N=1747$

\begin{tabular}{|c|c|c|c|c|c|c|c|}
\hline \multirow[t]{4}{*}{ Characteristics } & \multicolumn{6}{|c|}{ Maternal age group, years } & \multirow{4}{*}{$\begin{array}{l}\text { Adjusted } \\
x^{2}, P\end{array}$} \\
\hline & \multirow{2}{*}{\multicolumn{2}{|c|}{$\begin{array}{l}\leq 29 \\
(n=702)\end{array}$}} & \multirow{2}{*}{\multicolumn{2}{|c|}{$\begin{array}{l}30-34 \\
(n=677)\end{array}$}} & \multirow{2}{*}{\multicolumn{2}{|c|}{$\begin{array}{l}\geq 35 \\
(n=368)\end{array}$}} & \\
\hline & & & & & & & \\
\hline & $n$ & $\%$ & $\bar{n}$ & $\%$ & $n$ & $\%$ & \\
\hline \multicolumn{8}{|l|}{ Marital status } \\
\hline Maried/cohabited & 661 & 94.4 & 665 & 98.5 & 358 & 97.3 & \multirow[t]{2}{*}{$<0.001$} \\
\hline Single & 39 & 5.6 & 10 & 1.5 & 10 & 2.7 & \\
\hline \multicolumn{8}{|c|}{ Number of antenatal care visits } \\
\hline$<=12$ & 440 & 63.7 & 361 & 54.6 & 186 & 52.3 & \multirow[t]{2}{*}{$<0.05$} \\
\hline$>12$ & 251 & 36.3 & 300 & 45.4 & 170 & 47.7 & \\
\hline \multicolumn{8}{|l|}{ BMI $\left(\mathrm{kg} / \mathrm{m}^{2}\right)$} \\
\hline 18.5 to 25.0 & 446 & 63.5 & 429 & 63.4 & 213 & 57.9 & \multirow[t]{2}{*}{0.19} \\
\hline$>25$ & 256 & 36.5 & 248 & 36.6 & 155 & 44.1 & \\
\hline \multicolumn{8}{|l|}{ Height } \\
\hline$<1.5 \mathrm{~m}$ & 30 & 4.3 & 23 & 3.4 & 13 & 3.5 & \multirow[t]{2}{*}{0.44} \\
\hline$>1.5 \mathrm{~m}$ & 672 & 95.7 & 654 & 96.6 & 355 & 96.5 & \\
\hline $\begin{array}{l}\text { Pre-exiting medical } \\
\text { conditions }^{\mathrm{a}}\end{array}$ & 98 & 14.0 & 102 & 15.1 & 94 & 26.5 & $<0.001$ \\
\hline \multicolumn{8}{|c|}{ Health institutional type } \\
\hline Public & 312 & 44.4 & 239 & 35.3 & 130 & 35.3 & \multirow[t]{2}{*}{0.23} \\
\hline Private & 390 & 55.6 & 438 & 64.7 & 238 & 64.7 & \\
\hline
\end{tabular}

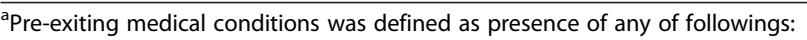
chronic hypertension, cardiac/renal diseases, chronic respiratory conditions, diabetes mellitus, sickle cell anaemia, severe anaemia and pyelonephritis or urinary infection

Study-design based Pearson's chi-2 test was calculated were less likely to deliver at private institutions (55.6\% vs $64.7 \%$ in women aged $30-34$ and $>35$ years).

Table 2 shows pregnancy and labour complications by age group in primiparous women with singleton births. The advanced maternal age group was more likely to have maternal hypertension ( $12.0 \%$ vs $4.3 \%$ in women aged $\leq 29$ years and $6.1 \%$ in women aged $30-34$ years), preterm birth $(8.7 \%$ vs $4.5 \%$ in women aged $\leq 29$ years and $5.2 \%$ in women aged $30-34$ years), elective CS $(10.3 \%$ vs $4.1 \%$ in women aged $\leq 29$ years and $6.8 \%$ in women aged 30-34 years) and emergency antepartum CS (6.5 \% vs $2.3 \%$ in women aged $\leq 29$ years and $3.7 \%$ in women aged 30-34 years) than other age groups.

Table 3 illustrated CS indications by age group in primiparous women with singleton births. The proportion of women who underwent CS for indication of preeclampsia/eclampsia, suspected fetal growth impairment and other obstetric and maternal complications were highest among women aged $>35$ years. However, these differences were not statistically significant. CS for indication of dystocia and other fetal complications were significantly higher in women aged $30-34$ years, whereas a significantly higher proportion of women aged $>35$ years had two and more indications for CS $(42.9 \%$ vs $33.7 \%$ in women aged $\leq 29$ years and $26.3 \%$ in women aged 30-34 years).

Table 4 showed risk factors for CS in primiparous women with singleton births. Compared to women aged $\leq 29$ years after adjustment for marital status, maternal height, preexisting maternal medical conditions, maternal hypertension, birth weight and type of health institution, risk of CS were 1.40 (95 \% CI 1.02-1.92) and 1.89 (95\% CI 1.28-2.78) times higher in women aged $30-34$ years and $>35$ years, respectively. Women aged $>35$ years had a significantly

Table 2 Pregnancy and labour complication by age groups in primiparous women with singleton births $N=1747$

\begin{tabular}{|c|c|c|c|c|c|c|c|}
\hline & \multicolumn{6}{|c|}{ Maternal age group, years } & \multirow{4}{*}{$\begin{array}{l}\text { Adjusted } \\
x^{2}, P\end{array}$} \\
\hline & \multirow{2}{*}{\multicolumn{2}{|c|}{$\begin{array}{l}\leq 29 \\
(n=702)\end{array}$}} & \multirow{2}{*}{\multicolumn{2}{|c|}{$\frac{30-34}{(n=677)}$}} & \multirow{2}{*}{\multicolumn{2}{|c|}{$\begin{array}{l}\geq 35 \\
(n=368)\end{array}$}} & \\
\hline & & & & & & & \\
\hline & $n$ & $\%$ & $n$ & $\%$ & $n$ & $\%$ & \\
\hline Maternal hypertension ${ }^{a}$ & 30 & 4.3 & 41 & 6.1 & 44 & 12.0 & $<0.001$ \\
\hline PROM & 171 & 24.4 & 157 & 23.2 & 90 & 24.5 & 0.85 \\
\hline Fetal growth impairment & 17 & 2.4 & 13 & 1.9 & 10 & 2.7 & 0.68 \\
\hline Preterm birth (<37 weeks) & 32 & 4.5 & 35 & 5.2 & 32 & 8.7 & $<0.05$ \\
\hline Low birth weight $(<2500 \mathrm{~g})$ & 77 & 10.1 & 70 & 10.3 & 50 & 13.7 & 0.11 \\
\hline Instrumental vaginal delivery & 53 & 7.6 & 59 & 8.7 & 43 & 11.7 & 0.08 \\
\hline Elective CS & 29 & 4.1 & 46 & 6.8 & 38 & 10.3 & $<0.01$ \\
\hline Emergency antepartum CS & 16 & 2.3 & 25 & 3.7 & 24 & 6.5 & $<0.05$ \\
\hline Intrapartum CS & 44 & 6.3 & 47 & 6.9 & 36 & 9.8 & 0.20 \\
\hline
\end{tabular}

CS caesarean section, $P R O M$ prelabour rupture of membrane

${ }^{a}$ Maternal hypertension was defined as presence of pregnancy-induced hypertension, preeclampsia and eclampsia Study-design based Pearson's chi- 2 test was calculated 
Table 3 CS indication by age group in primiparious women with singleton births $N=305^{\mathrm{a}}$

\begin{tabular}{|c|c|c|c|c|c|c|c|}
\hline \multirow[t]{4}{*}{ CS Indications } & \multicolumn{6}{|c|}{ Maternal age group, years } & \multirow{4}{*}{$\begin{array}{l}\text { Adjusted } \\
x^{2}, P\end{array}$} \\
\hline & \multirow{2}{*}{\multicolumn{2}{|c|}{$\begin{array}{l}\leq 29 \\
(n=89)\end{array}$}} & \multirow{2}{*}{\multicolumn{2}{|c|}{$\begin{array}{l}30-34 \\
(n=118)\end{array}$}} & \multirow{2}{*}{\multicolumn{2}{|c|}{$\begin{array}{l}\geq 35 \\
(n=98)\end{array}$}} & \\
\hline & & & & & & & \\
\hline & $\bar{n}$ & $\%$ & $\bar{n}$ & $\%$ & $\bar{n}$ & $\%$ & \\
\hline Pre-/eclampsia & 3 & 3.4 & 10 & 8.5 & 13 & 13.3 & 0.05 \\
\hline Suspected fetal growth impairment & 3 & 3.4 & 5 & 4.2 & 7 & 7.1 & 0.45 \\
\hline Fetal distress & 30 & 33.7 & 28 & 23.4 & 32 & 32.6 & 0.22 \\
\hline Dystocia & 20 & 22.5 & 40 & 33.9 & 17 & 17.4 & $<0.05$ \\
\hline Failed induction & 11 & 12.4 & 10 & 8.5 & 13 & 13.3 & 0.49 \\
\hline Breech/malpresentation & 31 & 34.8 & 29 & 24.6 & 29 & 29.6 & 0.27 \\
\hline Other maternal medical indications & 11 & 12.4 & 11 & 9.3 & 17 & 17.4 & 0.21 \\
\hline Other fetal indications & 4 & 4.5 & 10 & 8.5 & 1 & 1.0 & $<0.05$ \\
\hline Other obstetric indications & 14 & 15.7 & 17 & 14.4 & 26 & 26.5 & 0.05 \\
\hline Having 2 and more indications & 30 & 33.7 & 31 & 26.3 & 42 & 42.9 & $<0.05$ \\
\hline
\end{tabular}

CS caesarean section

${ }^{\text {a }}$ Total number of deliveries restricted to women who delivered by caesarean section

Other maternal medical indications included caesarean sections indicated for $3^{\text {rd }}$ trimester vaginal bleeding, suspected/imminent uterine rupture, genital herpes/ extensive condyloma and any other maternal medical complications. Other fetal indications included postmortem caesarean section and any other fetal indications. Other obstetric indications defined as conditions such as placenta previa without bleeding

Study-design based Pearson's chi-2 test was calculated

higher risk of emergency antepartum CS (AOR 2.26, $95 \%$ CI 1.49-3.40) compared to women aged $\leq 29$ years.

\section{Discussion}

To our knowledge, this is the first multiple facility-based study with a reasonable sample size focusing on the association between maternal age and CS in Japan. The strength of this secondary analysis was the pretested, standardised data collection form used to obtain individual and health facility risk factors for CS across randomly selected health facilities, therefore the study results could be generalisable to facilities in Japan.

We found that women having their first childbirth and aged $>35$ years more likely to have maternal hypertension and higher risk of all CS, elective CS and emergency antepartum CS.

After adjustment for potential confounding factors, risk of all CS and emergency antepartum CS were significantly higher in women aged $>35$ years compared to primiparous women aged $\leq 29$ years with singleton births. The proportion of women having CS indicated for preeclampsia/eclampsia, suspected fetal growth impairment, other obstetric and maternal complications, and having multiple indications were significantly higher in women aged $>35$ years [20]. Previous research also highlights the effect of advanced maternal age increasing the risk for CS and operative vaginal delivery in the Asian population [21]. However, previous studies have not explored whether elective or emergency CS differs by

Table 4 The association between maternal age and caesarean section in primiparious women with singleton births. Results of multivariable logistic regression analyses

\begin{tabular}{|c|c|c|c|c|c|c|c|c|c|}
\hline \multirow[b]{4}{*}{ All CS } & \multicolumn{9}{|c|}{ Maternal age, years } \\
\hline & \multirow{3}{*}{$\begin{array}{l}\leq 29 \\
\text { ref }\end{array}$} & \multicolumn{4}{|c|}{$30-34$} & \multicolumn{4}{|l|}{$\geq 35$} \\
\hline & & \multicolumn{2}{|c|}{ Crude OR (95 \% Cl) } & \multicolumn{2}{|c|}{ Adjusted OR (95 \% Cl) } & \multicolumn{2}{|c|}{ Crude OR (95\% Cl) } & \multicolumn{2}{|c|}{ Adjusted OR (95 \% Cl) } \\
\hline & & 1.45 & $(1.10-1.91)^{*}$ & 1.40 & $(1.02-1.92)^{*}$ & 2.50 & $(1.74-3.56)^{* * *}$ & 1.89 & $(1.28-2.78)^{* *}$ \\
\hline Elective CS & ref & 1.69 & $(1.11-2.55)^{*}$ & 1.55 & $(0.94-2.55)$ & 2.67 & $(1.54-4.61)^{* *}$ & 1.70 & $(0.88-3.30)$ \\
\hline Emergency antepartum CS & ref & 1.64 & $(0.68-3.97)$ & 1.76 & $(0.73-4.25)$ & 2.99 & $(1.94-4.61)^{* * *}$ & 2.26 & $(1.49-3.40)^{* *}$ \\
\hline Intrapartum CS & ref & 1.11 & $(0.63-1.98)$ & 1.05 & $(0.56-1.97)$ & 1.62 & $(0.97-2.69)$ & 1.44 & $(0.92-2.25)$ \\
\hline
\end{tabular}

Multivariable logistic regression analysis with adjustment study design effect and risk factors. Risk factors were included: marital status, height, pre-exiting medical conditions, maternal hypertension, birthweight and health institutions ownership. Pre-exiting medical conditions was defined as presence of any of followings: chronic hypertension, cardiac/renal diseases, chronic respiratory conditions, diabetes mellitus, sickle cell anaemia, severe anaemia and pyelonephritis or urinary infection. Maternal hypertension was defined as presence of pregnancy-induced hypertension, preeclampsia and eclampsia

CS caesarean section, ref reference group

${ }^{*}<0.05^{* *}<0.011^{* *}<0.001$ 
indication [16, 20-22]. As well as increasing risk for CS, delaying family planning increases the use of assisted reproduction technology, medical costs, and adverse outcomes [3]. To promote safe pregnancy and delivery, the development of supportive health policies and a community healthcare system is needed for younger as well as older mothers.

This study has several important limitations. First, the study findings are not generalisable to the whole country as it includes few facilities out of thousands. Second, this is cross-sectional study and we were not able to identify the cause-effect relationship of CS. However, to the best of our knowledge, it is the first study on maternal age and caesarean section that obtained data from multifacilities with most available data and indications on caesarean section in Japan.

\section{Conclusion}

In Japan, advanced maternal age significantly increased the risk for CS. However, intrapartum CS-which is generally undertaken for obstetric indications-was not higher risk among the older age group. Management of maternal complications would help to reduce the rate of CS and the associated medical consumption.

\section{Competing interests}

The authors declare that they have no competing interests.

This research was partially supported by the Ministry of Education, Science, Sports and Culture, Grant-in-Aid for Young Scientific Research (B), 2014-2015 (26860428). This research was supported by clinical research program for child health \& development.

\section{Authors' contributions}

KMY conducted analysis and drafted the manuscript. EO conducted project design, methodological issues. GT partly conducted analysis and drafting additional method. EO, GT, MK and RM assisted in manuscript revision. All authors read and approved the final manuscript.

\section{Acknowledgments}

We appreciate the editorial support of Ms. Emma Barber

\section{Author details}

${ }^{1}$ Department of Community Health Nursing, School of Nursing, Faculty of Medicine, Tokyo Medical University, Tokyo, Japan. ${ }^{2}$ Department of Health Policy, National Center for Child Health and Development, Tokyo, Japan.

${ }^{3}$ Faculty of Medicine, University of Tsukuba, Ibaraki, Japan.

Received: 25 September 2015 Accepted: 22 February 2016

Published online: 29 February 2016

\section{References}

1. Retherford RD, Ogawa N, Matsukura R. Late marriage and less marriage in Japan. Popul Dev Rev. 2001;27(1):65-102.

2. Astolfi P, Zonta LA. Delayed maternity and risk at delivery. Paediatr Perinat Epidemiol. 2002;16(1):67-72.

3. Tromp M, Ravelli AC, Reitsma JB, Bonsel GJ, Mol BW. Increasing maternal age at first pregnancy planning: health outcomes and associated costs. J Epidemiol Community Health. 2011;65(12):1083-90.

4. Bayrampour H, Heaman M. Advanced maternal age and the risk of cesarean birth: a systematic review. Birth. 2010;37(3):219-26.

5. Kenny LC, Lavender T, McNamee R, O'Neill SM, Mills T, Khashan AS. Advanced maternal age and adverse pregnancy outcome: evidence from a large contemporary cohort. PLoS One. 2013;8(2):e56583.
6. Kozinszky Z, Orvos H, Zoboki T, Katona M, Wayda K, Pal A, et al. Risk factors for cesarean section of primiparous women aged over 35 years. Acta Obstet Gynecol Scand. 2002;81(4):313-6.

7. Gibbons L, Belizan JM, Lauer JA, Betran AP, Merialdi M, Althabe F. Inequities in the use of cesarean section deliveries in the world. Am J Obstet Gynecol. 2012;206(4):331 e331-319.

8. Souza JP, Gülmezoglu AM, Lumbiganon P, Laopaiboon M, Carroli G, Fawole B, et al. Caesarean section without medical indications is associated with an increased risk of adverse short-term maternal outcomes: the 2004-2008 WHO Global Survey on Maternal and Perinatal Health. BMC Med. 2010;8(1):71.

9. Belizan JM, Althabe F, Cafferata ML. Health consequences of the increasing caesarean section rates. Epidemiology. 2007;18(4):485-6.

10. Organization WH. Appropriate technology for birth. Lancet. 1985;2(8452):436-7.

11. OECD, Health at a Glance 2011: OECD Indicators, OECD Publishing. Paris, France.http://dx.doi.org/10.1787/health_glance-2011-en.

12. Ministry of Health and Welfare, Japan. Trends in the number of deliveries and percentage of caesarean operations in healthcare facilities, 1984-2008. Health statistics of Japan in 2010. 2010: URL: http://www.mhlw.go.jp/toukei/ saikin/hw/hoken/national/dl/22-00.pdf.

13. Chihara I, Uehara R, Kotani K, Sadakane A, Aoyama Y, Tsuboi S, et al. The effect of prepregnancy body mass index on singleton cesarean delivery among term nulliparous women in Japanese population. Arch Gynecol Obstet. 2011:284(5):1117-22.

14. Isono W, Nagamatsu T, Uemura Y, Fujii T, Hyodo H, Yamashita T, et al. Prediction model for the incidence of emergent cesarean section during induction of labor specialized in nulliparous low-risk women. J Obstet Gynaecol Res. 2011;37(12):1784-91.

15. Takahashi H, Watanabe N, Sugibayashi R, Aoki H, Egawa M, Sasaki A, et al. Increased rate of cesarean section in primiparous women aged 40 years or more: a single-center study in Japan. Arch Gynecol Obstet. 2012;285(4):937-41.

16. Bilano VL, Ota E, Ganchimeg T, Mori R, Souza JP. Risk factors of preeclampsia/eclampsia and its adverse outcomes in low- and middle-income countries: a WHO secondary analysis. PLoS One. 2014;9(3):e91198.

17. Bukola F, Idi N, M'Mimunya M, Jean-Jose WM, Kidza M, Isilda N, et al. Unmet need for induction of labor in Africa: secondary analysis from the 20042005 WHO Global Maternal and Perinatal Health Survey (A cross-sectional survey). BMC Public Health. 2012;12:722

18. Karlsen S, Say L, Souza JP, Hogue CJ, Calles DL, Gulmezoglu AM, et al. The relationship between maternal education and mortality among women giving birth in health care institutions: analysis of the cross sectional WHO Global Survey on Maternal and Perinatal Health. BMC Public Health. 2011;11:606.

19. Lumbiganon P, Laopaiboon M, Gulmezoglu AM, Souza JP, Taneepanichskul $\mathrm{S}$, Ruyan $\mathrm{P}$, et al. Method of delivery and pregnancy outcomes in Asia: the WHO global survey on maternal and perinatal health 2007-08. Lancet. 2010; 375(9713):490-9.

20. Winkel S, Einsle F, Pieper L, Hofler M, Wittchen HU, Martini J. Associations of anxiety disorders, depressive disorders and body weight with hypertension during pregnancy. Archives of Women's Mental Health. 2015;18(3):473-483.

21. Hsieh TT, Liou JD, Hsu JJ, Lo LM, Chen SF, Hung TH. Advanced maternal age and adverse perinatal outcomes in an Asian population. Eur J Obstet Gynecol Reprod Biol. 2010;148(1):21-6.

22. Samuels-Kalow ME, Funai EF, Buhimschi C, Norwitz E, Perrin M, CalderonMargalit $R$, et al. Prepregnancy body mass index, hypertensive disorders of pregnancy, and long-term maternal mortality. Am J Obstet Gynecol. 2007; 197(5):490 e491-496.

Submit your next manuscript to BioMed Central and we will help you at every step:

- We accept pre-submission inquiries

- Our selector tool helps you to find the most relevant journal

- We provide round the clock customer support

- Convenient online submission

- Thorough peer review

- Inclusion in PubMed and all major indexing services

- Maximum visibility for your research

Submit your manuscript at www.biomedcentral.com/submit 